\title{
Hyperhomocysteinemia, a risk factor for arteriovenous fistula thrombosis in hemodialysis patients
}

\begin{abstract}
Purpose: Homocysteine, a putative risk factor of cardiovascular disease is considerably high in hemodialysis patients. The aim of this study was to identify the association between homocysteine level and occurrence of fistula thrombosis in newly developed hemodialytic patients with arteriovenous (AV) fistula.
\end{abstract}

Method: In this prospective study 120 patients with ESRD who were candidate for AV fistula insertion, were enrolled. The association between homocysteine level, age, sex, and underlying disease leaded to ESRD and incidence of AV fistula thrombosis was analyzed by means of Logistic Regression model.

Result: Of 120 patients (69 men, 51 women), the mean age was $57.64 \pm 1.54$ years. The mean serum tHcy value was $30.85 \pm 12.37 \mu \mathrm{mol}$. Hyperhomocysteinemia was presented in 106 patients (88.3\%). During 6 month of follow up, 14 patients $(11.7 \%)$ (9 men, 5 women) experienced fistula thrombosis. Logistic regression analysis demonstrated that tHcy level was significantly higher in patients with incident fistula thrombosis compared with patients without this event $(41.61 \pm 11.53$ vs. $29.43 \pm 11.94)(p<0.007)$. Homocysteine cutoff point was determined at $25 \mu \mathrm{mol} / \mathrm{L}$ (sensitivity $100 \%$ and specificity $36.6 \%$ ). Regarding to Logistic Regression model, each $10 \mu \mathrm{mol} / \mathrm{L}$ increases in plasma tHcy level will increase the risk of fistula thrombosis by $10.8 \%(95 \% \mathrm{CI}, 10$ to $12 \%)(\operatorname{Exp}(\mathrm{B})(\mathrm{OR})=1.85)$.

Conclusion: According to high incidence of VA thrombosis and Hyperhomocysteinemia in hemodialysis patients and strong association between thrombosis and Hyperhomocysteinemia, interventional studies are needed to show the effect of lowering homocysteine level before insertion of fistula on thrombotic events in this population.
Volume 3 Issue 3 - 2016

\author{
Hossein Hemmati, Ali Monfared, Seyyede \\ Zeinab Azimi, Abtin Heidar Zade, Terme \\ Khoshnevis \\ Vascular Surgery and Dialysis Research Center of Guilan \\ University of Medical sciences, Iran
}

Correspondence: Hossein Hemmati, Vascular Surgery and Dialysis Research Center of Guilan University of Medical sciences, Inflammatory Lung Disease Research Center of Guilan University Of Medical Sciences, Razi Hospital, Sardarjangal Ave, Rasht , Iran,Tel 98-I3-3354246, Email massahnias@yahoo.com

Received: September 05, 2016 | Published: July 6, 2016

Keywords: thrombosis, fistula, chronic renal failure, homocysteine

\section{Introduction}

Demographic data and underlying diseases had been recorded (Table 1). All patients were being treated with $5 \mathrm{mg}$ folic acid while no patient received ASA or warfarin. ${ }^{1}$ A fasting pre hemodialytic blood sample was obtained from all patients and plasma total homocysteine (tHcy) level was determined by means of Immunoturbidimetry Based on conversion $N A D H+$ to $N A D$. According to the history of venous puncture and the diameter of cephalic and basilic vein, the patients had been categorized into A (excellent), B (intermediate) and C (poor) group of fistula outcome (Table 2). 18 Patients who experienced AV fistula thrombosis at the first month and those who needed to dialysis during the study period had been excluded. ${ }^{2}$ A fistula thrombosis was considered as a fistula without bruit in auscultation or thrill in palpation which impaired hemodialysis and needed thrombectomy, thrombolysis or replacement of another vascular access. Continues variables were expressed as mean values with SDs. In the univariate analysis, Fisher exact test and independent $t$ test were used to test the significance of differences between two groups. ${ }^{3}$ In the multivariate analysis we used Logistic Regression model by Back LR method for determining the association between homocysteine levels, age, sex, and underlying disease leaded to ESRD and incidence of AV fistula thrombosis. Odds ratio and $95 \%$ confidence intervals were also calculated. The association between outcome of AV fistula and AV thrombosis was analyzed by Post Hoc Test -ANOVA- analysis.
ROC curve has been used to identify the cutoff point of homocysteine level for AV thrombosis. All calculations were carried out using SPSS, version 16. $\mathrm{P}$ value less than 0.05 was considered significant. ${ }^{4}$

\section{Results}

Of 120 patients ( 69 men, 51 women), the mean age was $57.64 \pm 1.54$ years (range 18 -88). The mean serum tHcy value was $30.85 \pm 12.37$ $\mu \mathrm{mol} / \mathrm{L}$ (range 5-72); in group A, it was $29.71 \pm 11.55 \mu \mathrm{mol} / \mathrm{L}$; in group $\mathrm{B}, 32.70 \pm 13.73 \mu \mathrm{mol} / \mathrm{L}$ and in group $\mathrm{C}, 30.84 \pm 12.42 \mu \mathrm{mol} / \mathrm{L}$. However the mean level of homocysteine was higher in group B, but there was no statically significant difference between three groups (Figure 1). Hyperhomocysteinemia was presented in 106 patients (88.3\%) (Cut off, $>15$ in patient $<50 \mathrm{yr}$ and cut off $>20$ in patient $>50 \mathrm{yr}$ ). During 6 month of follow up (the mean time needed for maturation of fistula), 14 patients (11.7\%) (9 men, 5 women) experienced fistula thrombosis. ${ }^{5}$ Their mean age was $61.14 \pm 9.60$ years. Univariate analysis analysis demonstrated that tHcy level was significantly higher in patients with incident fistula thrombosis compared with patients without this event $(41.54 \pm 11.64$ vs. $29.37 \pm 11.77)(\mathrm{p}=0.002) .{ }^{6}$ There was no statistically significant association between age, sex, underlying disease and fistula thrombosis (Table 3). In multivariate analysis, regarding to Logistic Regression model, each $10 \mu \mathrm{mol} / \mathrm{L}$ increases in plasma tHcy level will increase the risk of fistula thrombosis by 2.3 times ( $95 \%$ CI, 1.34 to $3.97 \%)^{7}$ After adjusting for age, sex and underlying diseases each 10 $\mu \mathrm{mol} / \mathrm{L}$ increases in plasma tHcy level will increase the risk of fistula 
thrombosis by 2.08 times (95\% CI, 1.32 to 3.28 times) (Table 4). Homocysteine cutoff point was determined at $25 \mu \mathrm{mol} / \mathrm{L}$ (sensitivity $100 \%$ and specificity $36.6 \%$ ) (Figure 2 ).

Table I Demographic and clinical data about the study population

\begin{tabular}{ll}
\hline Age (y) & $\mathbf{5 7 . 6 4 \pm 1 5 . 4 9}$ \\
\hline Sex: & \\
Male & $69(57.5 \%)$ \\
Female & $5 \mathrm{I}(42.5 \%)$ \\
Etiology of ESRD: & \\
Diabetes Mellitus (DM) & $\mathrm{II}(9.2 \%)$ \\
Glomerulonephritis & $4(3.3 \%)$ \\
Hypertension (HTN) & $62(51.7 \%)$ \\
DM \& HTN & $21(17.5 \%)$ \\
Obstructive Nephropathy & $2(1.7 \%)$ \\
PCKD & $1(0.8 \%)$ \\
Nephrolithiasis & $4(3.3 \%)$ \\
Unknown & $12(10 \%)$ \\
UTI & $3(2.5 \%)$ \\
Fistula Outcome: & \\
Group A & $55(45.6 \%)$ \\
Group B & $47(39.2 \%)$ \\
Group C & $18(15 \%)$
\end{tabular}

NOTE: Data expressed as mean $\pm S D$ or number (percent), as appropriate. PCKD: Polycystic Kidney Disease; UTI: Urinary Tract Infection

Table 2 Groups of fistula outcome

\begin{tabular}{llll}
\hline & Group A & Group B & Group C \\
\hline $\begin{array}{l}\text { The Alien Test(Sec) } \\
\text { Diameter of Cephalic }\end{array}$ & $>3$ & $5-$ Mar & $>5$ \\
$\begin{array}{l}\text { Vein(mm) } \\
\begin{array}{l}\text { Diameter of Basilic } \\
\text { Vein(mm) }\end{array}\end{array}$ & $>3$ & $1.5-2.5$ & $<1.5$ \\
$\begin{array}{l}\text { Puncture of Vein } \\
\text { No }\end{array}$ & Yes & Yes (multiple) \\
\hline
\end{tabular}

\section{Discussion}

The main aim of the present study was to determine the relationship between the level of homocysteine and fistula thrombosis in patients with ESRD who were candidate for $\mathrm{AV}$ fistula insertion. ${ }^{8}$ VA thrombosis is a major problem in the care of hemodialysis patients. Fistula thrombosis rate in our study was $11.7 \%$. The high prevalence of Hyperhomocysteinemia (88.3\%) was similar to that reported in other studies..$^{9-11}$ It has been shown in many previous studies that hHcy is an independent risk factor for both arterial and venous thrombosis in the general population. ${ }^{12}$ Shemin and associates demonstrated that even mild Hyperhomocysteinemia is an independent risk factor for VA thrombosis in hemodialysis patients. 47 patients $(59 \%)$ had one episode of access thrombosis and they had higher mean level of total plasma homocysteine $(26.1 \pm 11.6$ vs. $20.9 \pm 7.8 \mu \mathrm{mol} / \mathrm{L}) .{ }^{13}$ However Moustapha et al. ${ }^{14}$ could not find any association between hHcy and
VA thrombosis. Mallamaci and colleagues showed that 78 patients $(38.4 \%)$ who had been on regular hemodialysis treatment for at least 6 months, the total homocysteine level was significantly higher in patients with incident thrombosis $(28.9$ vs. $25.5 \mu \mathrm{mol} / \mathrm{L}, \mathrm{P}=0.046){ }^{15}$ To our knowledge the present study is the first cohort study which evaluated patients with native AV fistula from the beginning of AV fistula insertion. In our study there was strong association between Hyperhomocysteinemia and fistula thrombosis, which was compatible with Mallamaci and Shemin's studies. ${ }^{15,13}$

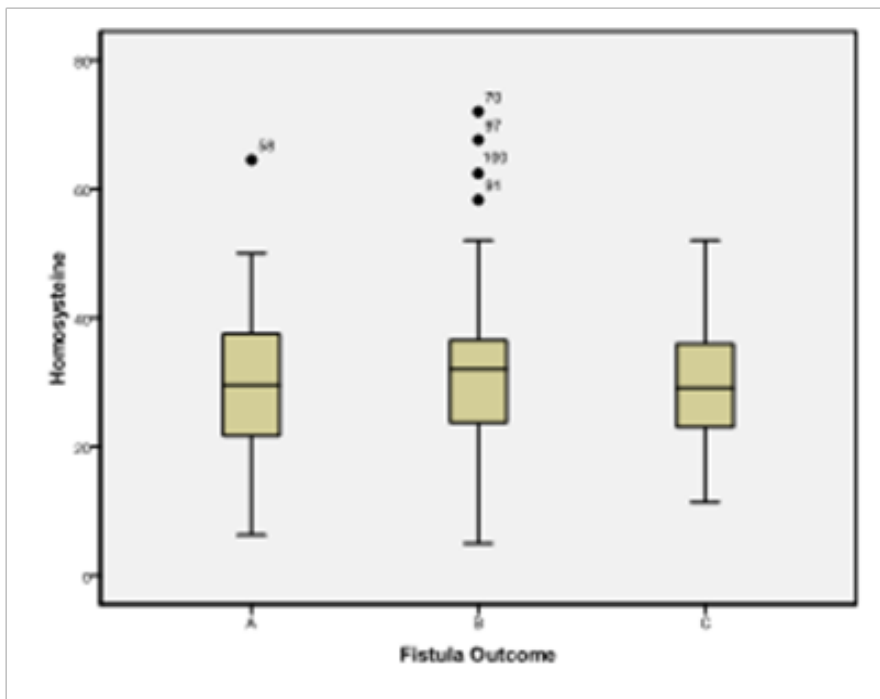

Figure I Mean level of homocysteine $(\mu \mathrm{mol} / \mathrm{L})$ in different fistula outcome groups.

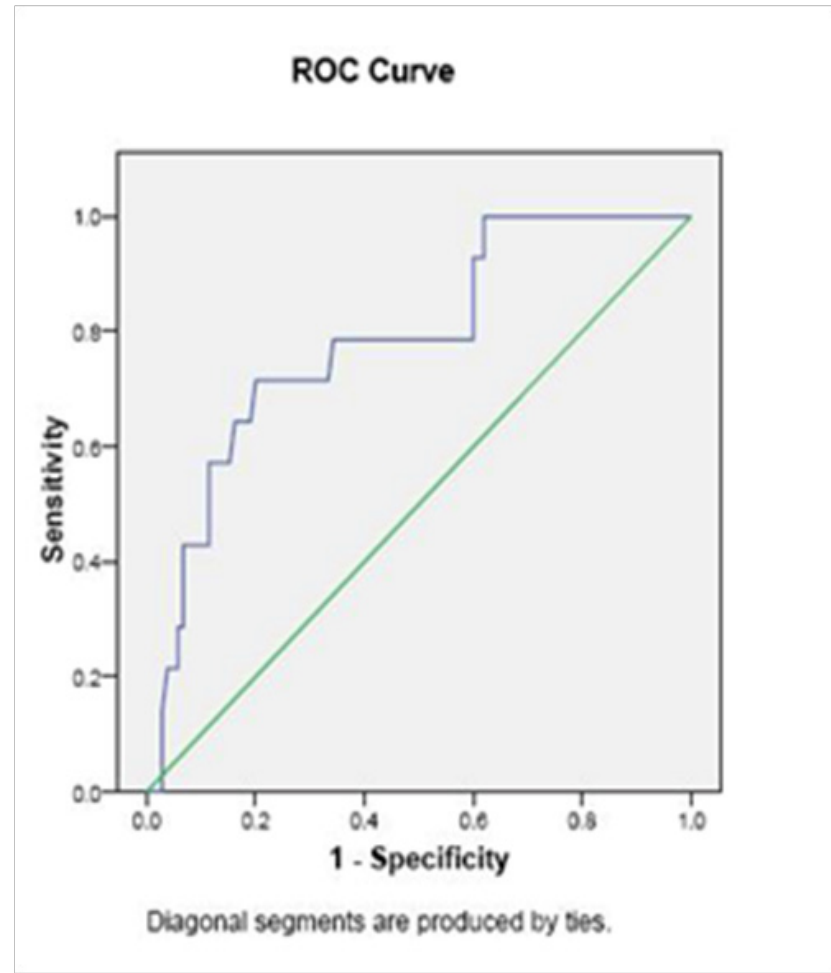

Figure 2 ROC Curve to determine the homocysteine cutoff point. 
Table 3 Univariate analysis

\begin{tabular}{|c|c|c|c|c|c|c|}
\hline & & \multicolumn{4}{|c|}{ Developed Venous Thrombosis During Follow Up Period } & \multirow[t]{2}{*}{$\mathbf{p}$} \\
\hline & & NO & & YES & & \\
\hline Age & & Count & Row N \% & Count & Row N\% & \\
\hline tHcy & & \multicolumn{2}{|c|}{$57.00 \pm 16.00$} & \multicolumn{2}{|c|}{$61.00 \pm 10.00$} & 0.199 \\
\hline Gender & Male & 60 & $87.00 \%$ & 9 & $13.00 \%$ & 0.403 \\
\hline Diabetes Mellitus (DM) & Female & 46 & $90.20 \%$ & 5 & $9.80 \%$ & \\
\hline Glomerulonephritis & NO & 32 & $86.50 \%$ & 5 & $13.50 \%$ & 0.443 \\
\hline Obstructive Nephropathy & YES & 74 & $89.20 \%$ & 9 & $10.80 \%$ & \\
\hline PCKD & NO & 87 & $87.90 \%$ & 12 & $12.10 \%$ & $0.54 I$ \\
\hline Nephrolithiasis & YES & 19 & $90.50 \%$ & 2 & $9.50 \%$ & \\
\hline UTI & NO & 102 & $87.90 \%$ & 14 & $12.10 \%$ & 0.605 \\
\hline \multirow{10}{*}{ Fistula Outcome } & YES & 0 & $0.00 \%$ & 1 & $100.00 \%$ & \\
\hline & NO & 103 & $88.80 \%$ & 13 & II. $20 \%$ & 0.395 \\
\hline & YES & 3 & $75.00 \%$ & I & $25.00 \%$ & \\
\hline & NO & 103 & $88.00 \%$ & 14 & $11.70 \%$ & 0,687 \\
\hline & YES & 3 & $100.00 \%$ & 0 & $0.00 \%$ & \\
\hline & NO & 94 & $87.00 \%$ & 14 & $13.00 \%$ & 0.209 \\
\hline & YES & 12 & $100.00 \%$ & 0 & $0.00 \%$ & \\
\hline & $A$ & 49 & $89.10 \%$ & 6 & $10.90 \%$ & 0.773 \\
\hline & B & 42 & $89.40 \%$ & 5 & $10.60 \%$ & \\
\hline & C & 15 & $83.30 \%$ & 3 & $16.70 \%$ & \\
\hline
\end{tabular}


Table Continued

\begin{tabular}{|c|c|c|c|c|c|c|}
\hline & & \multicolumn{4}{|c|}{ Developed Venous Thrombosis During Follow Up Period } & \multirow[t]{2}{*}{$\mathbf{p}$} \\
\hline & & No & & YE & & \\
\hline \multirow[t]{2}{*}{ tHcy } & & \multicolumn{2}{|c|}{$57.00 \pm 16.00$} & \multicolumn{2}{|c|}{$61.00 \pm 10.00$} & 0.199 \\
\hline & & \multicolumn{2}{|c|}{$29.37 \pm I I .77$} & \multicolumn{2}{|c|}{$41.54 \pm 11.64$} & 0.002 \\
\hline Gender & Male & 60 & $87.00 \%$ & 9 & $13.00 \%$ & 0.403 \\
\hline Diabetes Mellitus (DM) & Female & 46 & $90.20 \%$ & 5 & $9.80 \%$ & \\
\hline Hypertension (HTN) & NO & 78 & $88.60 \%$ & 10 & $1 \mathrm{I} .40 \%$ & 0.544 \\
\hline Obstructive Nephropathy & YES & 74 & $89.20 \%$ & 9 & $10.80 \%$ & \\
\hline PCKD & NO & 87 & $87.90 \%$ & 12 & $12.10 \%$ & 0.541 \\
\hline Nephrolithiasis & YES & 19 & $90.50 \%$ & 2 & $9.50 \%$ & \\
\hline UTI & NO & 102 & $87.90 \%$ & 14 & $12.10 \%$ & 0.605 \\
\hline UN_KNOWN & YES & 4 & $100.00 \%$ & 0 & $0.00 \%$ & \\
\hline \multirow{9}{*}{ Fistula Outcome } & NO & 103 & $88.80 \%$ & 13 & $11.20 \%$ & 0.395 \\
\hline & YES & 3 & $75.00 \%$ & I & $25.00 \%$ & \\
\hline & NO & 103 & $88.00 \%$ & 14 & I I. $70 \%$ & 0,687 \\
\hline & YES & 3 & $100.00 \%$ & 0 & $0.00 \%$ & \\
\hline & NO & 94 & $87.00 \%$ & 14 & $13.00 \%$ & 0.209 \\
\hline & YES & 12 & $100.00 \%$ & 0 & $0.00 \%$ & \\
\hline & $A$ & 49 & $89.10 \%$ & 6 & $10.90 \%$ & 0.773 \\
\hline & B & 42 & $89.40 \%$ & 5 & $10.60 \%$ & \\
\hline & C & 15 & $83.30 \%$ & 3 & $16.70 \%$ & \\
\hline
\end{tabular}

Table 4 Multivariate Logistic Regression

\begin{tabular}{lcccc}
\hline & Standard Error & Significance & Odds Ratio & 95\% Confidence Intervals for Odds Ratio \\
\hline & Unadjusted & & Lower \\
\hline $\begin{array}{l}\text { Hyperhomocysteinemia } \\
\text { Adjusted by age, sex, underlying diseases }\end{array}$ & 0.28 & 0.003 & 2.31 & 1.34 \\
Hyperhomocysteinemia & 0.23 & & & \\
\hline
\end{tabular}


Use of synthetic grafts and biochemical factors such as hyperhomocysteinemia, high lupus anticoagulant, Leiden factor polymorphism are the predisposing factors of VA failure. ${ }^{16}$ Contrary to the above mentioned studies, in which, the population composed mainly of patients with AV fistula or arterial graft, the population in our study was merely the patients with native AV fistula. Of note, this study considered the patients in the time of maturation of fistula. Furthermore, no patient entered in the study had patency problems, in this way we tried to minimize the mechanical effects leading to VA thrombosis. Although thrombosis risk and plasma levels of homocysteine are greater in men than female, ${ }^{17-19}$ but we failed to show this association in our study. The interpretation of results revealed no association between etiology of ESRD and VA thrombosis. The short time of fallow up and small number of patients with specific cause of ESRD may be the reason of this finding. The thrombosis rate in our study $(11.7 \%)$ was lower than that in hemodialysis patients $(20 \%){ }^{20}$ this remains the question whether minimizing the mechanical effects such as vein puncture could result in this effect. In Shemin study it was yielded that each $1 \mu \mathrm{mol} / \mathrm{L}$ increase in homocysteine level could increase the risk of VA thrombosis by $4 \%{ }^{21}$ The Logistic Regression Model estimated that each $10 \mu \mathrm{mol} / \mathrm{Lit}$ increase in homocysteine level would increase the risk 2.3 times and after adjustment it would be 2.08 times. ${ }^{22}$ In regard to high incidence of VA thrombosis and hyperhomocysteinemia in hemodialysis patients and strong association between thrombosis and hyperhomocysteinemia, interventional studies are needed to show the effect of lowering homocysteine level before insertion of fistula on thrombotic events in this population. ${ }^{23,24}$

\section{Acknowledgments}

None.

\section{Conflicts of interest}

The author declares there is no conflict of interest.

\section{References}

1. Hsu CH, Vittinghoff E, Lin F, et al. The Incidence of End-Stage Renal Disease Is Increasing Faster than the Prevalence of Chronic Renal Insufficiency. Ann Intern Med. 2004;141(2):95-101.

2. Hojs R, Gorenjak M, Ekart R, et al. Homocysteine and vascular access thrombosis in hemodialysis patients. Ren Fail. 2002;24(2):215-222.

3. Feldman HI, Kobrin S, Wasserstein A. Hemodialysis vascular access morbidity. J Am Soc Nephrol. 1996;7(4):523-535 .

4. Woods JD, Turenne MN, Strawderman RL, et al. Vascular access survival among incident hemodialysis patients in the United States. $\mathrm{Am}$ J Kidney Dis. 1997;30(1):50-57 .

5. Windus DW, Jemdrisak MD, Delmez JA. Prosthetic fistula survival and complications in hemodialysis patients: Effects of diabetes and age. $\mathrm{Am}$ J Kidney Dis. 1992;19(5):448-452.

6. Wilson PWF, Castelli WP, Kannel WB. Coronary risk prediction in adults (the Framingham Heart Study). Am J Cardiol. 1987;59:91G-94G.

7. MA KW, Greene EL, Raij L. Cardiovascular risk factors in chronic renal failure and hemodialysis populations. Am J Kidney Dis. 1992;19(6):505513.
8. Christen WG, Ajani UA, Glynn RJ, et al. Blood levels of homocysteine and increased risk of cardiovascular disease Causal or Casual. Arch Intern Med. 2000;160(4):422-434.

9. Bostom AG, Siemin D, Lapane KL, et al. Hyperhomocysteinemia, hyperfibrinogenemia, and lipoprotein (a) excess in maintenance dialysis patients: A matched case-control study. Atherosclerosis. 1996;125(1):91-101.

10. Bostom AG, Siemin D, Verhoef P, et al. Elevated fasting total plasma homocysteine levels and cardiovascular disease outcomes in maintenance dialysis patients: A prospective study. Arteriosclerosis Thromb Vasc Biol. 1997;17(11):2554-2558.

11. Bostom AG, Lathrop L. Hyperhomocysteinemia in end-stage renal disease: Prevalence, etiology, and potential relationship to arteriosclerotic outcomes. Kidney Int. 1997;52(1):10-20.

12. Ducloux D, Pascal B, Jamali M, et al. Is hyperhomocysteinemia a risk factor for recurrent vascular access thrombosis in hemodialysis patients? Nephrol Dial Transplant. 1997;12(9):2037-2038.

13. Shemin D, Lapane KL, Bausserman L, et al. Plasma Total Homocysteine and Hemodialysis Access Thrombosis. $J$ Am Soc Nephrol. 1999;10(5):1095-1099.

14. Moustapha A, Naso A, Nahlawi M, et al. Prospective study of hyperhomocysteinemia as an adverse cardiovascular risk factor in endstage renal disease. Circulation. 1998;97:138-141.

15. Mallamaci F, Bonanno G, Seminara G, et al. Hyperhomocysteinemia and Arteriovenous Fistula thrombosis in hemodialysis patients. Am J Kidney. 2005;45(4):702-707.

16. Tamura T, Bergman SM, Morgan SL. Homocysteine, B-vitamins, and vascular access thrombosis in patients treated with hemodialysis. Am J Kidney Dis. 1998;32(3):475-481.

17. Wrone EM, Zehnder JL, Hornberger JM, et al. An MTHFR variant, homocysteine, and cardiovascular comorbidity in renal disease. Kidney Int. 2001;60:1106-1113.

18. Manns BJ, Burgess ED, Parsons HG, et al. Hyperhomocysteinemia, anticardiolipin antibody status, and risk for vascular access thrombosis in hemodialysis patients. Kidney Int. 1999;55(1):315-320.

19. Bowden RG, Wyatt FB, Wilson R. Homocysteine and vascular access thrombosis in end-stage renal disease patients: a retrospective study. JNephrol. 2002;15(6):666-670.

20. Sirrs S, Duncan L, Djurdjev O, et al. Homocyst(e)ine and vascular access complications in haemodialysis patients (Insights into a complex metabolic relationship). Nephrol Dial Transplant. 1999;14(3):738-743.

21. Stam F, Van Guldener C, Ter Wee PM, et al. Effect of folic acid on methionine and homocysteine metabolism in end stage - renal disease. Kidney Int. 2005;67(1):259-264.

22. Kikura M, Takada T, Sato S. Age- and sex-specific incidence, risk, and latency period of a perioperative acute thromboembolism syndrome (PATS). Thromb Haemost. 2004;91(4):725-732.

23. Wilson E. Thrombosis, venous hypertension, arterial steal syndrome and neuropathy. Vascular access principles and practice. Lakers, 2002. p. $175-188$.

24. Wilmore DW, Chung LY, Holcroft JW. ACS Surgery. Principles and practice. Web Med Corporation, 2002. 898 p. 